\title{
In vitro interferon $\gamma$ improves the oxidative burst activity of neutrophils in patients with chronic granulomatous disease with a subtype of gp91phox deficiency
}

\author{
SERKAN FILIZI, DILARA F. KOCACIK UYGUN², SADI KÖKSOY, EMEL ŞAHIN ${ }^{3}$, OLCAY YEĞIN² \\ ${ }^{1}$ Department of Paediatric Allergy and Immunology, Antalya Research and Training Hospital, Antalya, Turkey \\ ${ }^{2}$ Department of Paediatric Allergy and Immunology, Akdeniz University, Antalya, Turkey \\ ${ }^{3}$ Department of Microbiology and Immunology, Akdeniz University, Antalya, Turkey
}

\begin{abstract}
Aim of this study: Chronic granulomatous disease (CGD) is a genetically heterogeneous primary immunodeficiency caused by a defect in phagocyte production of oxygen metabolites, and resulting in infections produced by catalase-positive microorganisms and fungi. Interferon $\gamma($ IFN- $\gamma)$ has a multitude of effects on the immune system. Although preliminary studies with CGD patients on treatment with $I F N-\gamma$ showed that it enhanced phagocytosis and superoxide production, ongoing studies did not reveal a significant increase of this function. Here we investigated the oxidative capacity of phagocytes in different subtypes of CGD patients on treatment with IFN- $\gamma$ in vitro.

Material and methods: Fifty-seven patients with CGD from 14 immunology centres were enrolled to our multi-centre study. Twenty-one patients were studied as controls. Oxidative burst assay with dihydrorhodamine 123 (DHR) was used and the stimulation index (SI) was calculated with respect to CGD subtypes in both neutrophils and monocytes before, and then one and 24 hours after adding $I F N-\gamma$.

Results: Upon comparison of the SIs of the patients' neutrophils before in vitro IFN- $\gamma$ at hour 0 , and after adding IFN- $\gamma$ at hour 1 and 24 were compared, and the differences were determined between hours 0-24 and hours 1-24. This difference was especially apparent between hours 1-24. In CGD subtypes, particularly in gp91phox subtype, it was seen that, following in vitro IFN- $\gamma$, SIs of neutrophils began to increase after hour 1, and that increase became more apparent at hour 24.

Conclusions: Our study showed that IFN- $\gamma$ treatment may increase the oxidative bursting activity by increasing the superoxide production in neutrophils, particularly in gp91phox subtype.
\end{abstract}

Key words: neutrophils, monocytes, interferon $\gamma$, chronic granulomatous disease.

(Centr Eur Immunol 2015; 40 (1): 54-60)

\section{Introduction}

Chronic granulomatous disease (CGD) is a heterogeneous, inherited primary immunodeficiency disease that develops in connection with the defects in the nicotinamide adenine dinucleotide phosphate (NADPH) oxidase system that is necessary for respiratory burst and superoxide production of phagocytic cells, characterised by life-threatening infections recurring with some bacteria and fungi, and inflammatory response related to granuloma formation [1]. Nicotinamide adenine dinucleotide phosphate develops in connection with the mutations in five different gene structures of the oxidase system (gp91 ${ }^{\text {phox }}, \mathrm{p} 22^{\text {phox }}, \mathrm{p} 47^{\text {phox }}$ and p67 $\left.7^{\text {phox }}, \mathrm{p} 40^{\text {phox }}\right)[2]$.
Diagnosis is made by the medical history, clinical findings, and neutrophil function tests showing that the respiratory burst does not occur, and it is confirmed by genotyping. The treatment approaches such as prophylaxis with antibacterial, antifungal and interferon $\gamma$ (INF- $\gamma$ ), treatment of the acute infections and granulomatous complications, and curative approaches such as haematopoietic stem cell transplantation and gene therapy can be applied [3-5].

Interferon $\gamma$ is a cytokine with antiviral, antimicrobial, and anti-tumoural properties that is released by natural killer (NK) and natural killer T (NKT) cells, and that takes part in the natural and acquired immune system in the response to infections [6]. Although it has been used in CGD

Correspondence: Serkan Filiz, MD, Department of Paediatric Allergy and Immunology, Antalya Research and Training Hospital, Varlık Mahallesi, 07050 Muratpaşa/Antalya, Turkey, e-mail: serkanfiliz75@gmail.com 
since the 90 s, and a multitude of studies on its efficacy have been conducted, its place and efficacy in treatment is still controversial. Although earlier studies demonstrate its longterm therapeutic effect on the oxidative metabolism and functional effects on the NADPH oxidase enzyme system, such as bacteria killing and cytochrome b558, recent studies show that the clinical efficiency of the IFN- $\gamma$ treatment is not through NADPH oxidase activity [7-11]. It is included within the treatment protocols because the reduction in the frequency of infections and hospitalisation and recovery of quality of life can be achieved without serious toxicity [12]. Because many studies on the IFN- $\gamma$ treatment in CGD have been conducted before modern antimicrobial and antifungal prophylaxis treatment, new studies on the efficiency of IFN- $\gamma$ treatment are necessary. It is important to put into practice a convenient and affordable method that can predict whether the use of IFN- $\gamma$ will be efficient in CGD, which is a genetically heterogeneous disease. In this regard, in our study, oxidative bursting capacities of phagocytic cells in the patients with CGD in connection with different genotypes were measured, the effect of IFN- $\gamma$ on this activity was examined in vitro, and the interrelationships of all clinical and laboratory data were investigated.

\section{Material and methods}

\section{Study population}

Fifty-seven patients with CGD, who had been diagnosed on the basis of abnormal neutrophil function test defined by nitroblue tetrazolium reduction (NBT) test and DHR (dihydrodamine), were enrolled in this multicentre retrospective cohort. Patients on treatment with/without IFN- $\gamma$ from 14 immunology research institutes in Turkey were evaluated in our centre between October 2011 and June 2012. Fifty-four (95\%) patients received antibiotic prophylaxis with trimethoprim-sulfamethoxazole (usually $5 \mathrm{mg} / \mathrm{kg}$ b.i.d) and fifty-one ( $89 \%$ ) of them received anti-fungal prophylaxis with itraconazole $(100 \mathrm{mg}$ daily for patients $<50 \mathrm{~kg} ; 200 \mathrm{mg}$ daily for those $\geq 50 \mathrm{~kg}$ ). In addition to antibiotic and anti-fungal prophylaxis, thirty-four of the patients received IFN- $\gamma\left(50 \mu \mathrm{g} / \mathrm{m}^{2}\right)$ subcutaneously three times weekly. The patients had neither clinical infection nor hospitalisation at the time of the study. Also, they had not received systemic steroid or other immunosuppressive treatment during the study. A questionnaire including the patients' medical history was obtained from their hospital records. The demographic and clinical data including family history, consanguinity of the parents, initial diagnosis age, receiving prophylaxis therapy, and clinical manifestations before and after IFN- $\gamma$ treatment were recorded as well. Twenty-one patients, of which 9 were female and 12 were male, with a median age of 15 (range: 1.5-35) years, were studied as controls. They were healthy volunteers who had not taken any drug for at least seven days and also had not been affected with any infection before the study. Peripheral venous blood samples were obtained prior to IFN- $\gamma$ administration between 8 and 9 a.m., at the same time as sampling from patients not receiving IFN- $\gamma$.

Informed consent was obtained from each healthy volunteer and all patients with CGD, or from their guardians, before their enrolment to the study. The study was approved by the Medical Ethics Committee of Akdeniz University.

\section{Blood samples and pretreatment with interferon $\gamma$}

Whole blood samples were obtained from healthy controls and CGD patients using heparinised Vacutainer tubes (Becton Dickinson, Plymouth PL6 7BP, UK). Blood samples taken from patients in various hospitals were used within 10-30 minutes after reaching the laboratory. Blood samples were incubated with or without IFN- $\gamma\left(\right.$ Imukin $^{\circledR}$, Boehringer Ingelheim, $2 \times 10^{6} \mathrm{U} / 0.5 \mathrm{ml}$; at a final concentration of $100 \mathrm{U} / \mathrm{ml}$ ) for 1 hour and 24 hours at $37^{\circ} \mathrm{C}$ by using 15-ml BD Falcon conical polypropylene tubes (BD Biosciences Discovery Labware, Bedford, MA).

\section{Oxidative burst assay using dihydrorhodamine 123}

The principle of this method is the oxidation of nonfluorescent dihydrorhodamine 123 (DHR, Anaspec Inc., Fremont CA) by hydrogen peroxide, produced during the activated neutrophil respiratory oxidative burst, to rhodamine 123, a green fluorescent compound that can be detected by flow cytometry when phagocytised by normal activated neutrophils after stimulation with Phorbol Myristate Acetate (PMA) as described by Hawley et al. [13]. Dihydrorhodamine 123 and phorbol 12-myristate 13-acetate (PMA, AppliChem, Darmstadt, Germany) were dissolved in dimethyl sulfoxide (DMSO, Sigma Chemical Co., St. Louis, MO) at a concentration of $5 \mathrm{mg} / \mathrm{ml}$ and stored in aliquots at $-80^{\circ} \mathrm{C}$. Erythrocyte lysing solution (10X: 4.15 $\mathrm{g} \mathrm{NH}_{4} \mathrm{Cl}, 0.42 \mathrm{~g} \mathrm{NaHCO}_{3}$ and $1 \mathrm{ml} 0.5 \mathrm{M}$ EDTA in $50 \mathrm{ml}$ of deionised water) was diluted $1: 10$ with deionised water at the time of the experiment. Dihydrorhodamine 123 and PMA working solutions were prepared at concentrations of $50 \mu \mathrm{g} / \mathrm{ml}$ and $10 \mu \mathrm{g} / \mathrm{ml}$, respectively. Three tubes were labelled for each sample: Tube 1: No dye (DHR-)/unstimulated (PMA-); Tube 2: Plus dye (DHR+)/unstimulated (PMA-); Tube 3: Plus dye (DHR+)/stimulated (PMA+). Briefly, $100 \mu \mathrm{l}$ of well-mixed heparinised whole blood was diluted with $900 \mu \mathrm{l}$ of phosphate buffer saline (PBS, $\mathrm{Ca}^{2+}$ $-\mathrm{Mg}^{2+}$ free, Sigma Chemical Co., St. Louis, MO). $25 \mu \mathrm{l}$ of DHR working solution $(50 \mu \mathrm{g} / \mathrm{ml})$ was added to tubes 2 and 3 (final concentration: $1.21 \mu \mathrm{g} / \mathrm{ml}$ ) and incubated for 15 minutes at $37^{\circ} \mathrm{C}$. After incubation, $10 \mu \mathrm{l}$ of PMA working solution $(10 \mu \mathrm{g} / \mathrm{ml})$ were added to Tube 3 (final concentration: $\approx 100 \mathrm{ng} / \mathrm{ml}$ ), and all tubes were incubated for 15 minutes at $37^{\circ} \mathrm{C}$. After incubation, the tubes were 
Table 1. Demographic characteristics of 57 patients with chronic granulomatous disease

\begin{tabular}{|c|c|c|}
\hline \multicolumn{2}{|c|}{ CGD subtype (protein defect) } & $(n=57)$ \\
\hline & gp91 phox & $16 / 57(28.1 \%)$ \\
\hline & p22 phox & $10 / 57(17.5 \%)$ \\
\hline & p47 phox & $10 / 57(17.5 \%)$ \\
\hline & p67 phox & $6 / 57(10.5 \%)$ \\
\hline & not determined & $15 / 57(26.3 \%)$ \\
\hline \multirow[t]{12}{*}{ Sex } & $14(25 \%)$ female & $43(75 \%)$ male \\
\hline & $\begin{array}{l}\text { No. }(\%) \text { of patients with } \\
\text { X-linked inheritance }\end{array}$ & $16(28 \%)$ male \\
\hline & $\begin{array}{l}\text { No. }(\%) \text { of patients with } \\
\text { autosomal recessive or not } \\
\text { determined }\end{array}$ & $\begin{array}{c}\text { female } 14 / 41(34 \%) \\
\text { male } 27 / 41(66 \%)\end{array}$ \\
\hline & $\begin{array}{c}\text { Age at diagnosis, median } \\
\text { (range) }\end{array}$ & 4.8 years (birth to 19 years) \\
\hline & Current age, mean \pm SD & $10.9 \pm 7.4$ \\
\hline & No. (\%) of consanguinity & $33 / 57(56 \%)$ \\
\hline & $\begin{array}{l}\text { No. of the family history } \\
\text { of PID }\end{array}$ & $34 / 57(60 \%)$ \\
\hline & $\begin{array}{l}\text { No. }(\%) \text { of patients receiving } \\
\text { TMP-SMX prophylaxis }\end{array}$ & $54 / 57(95 \%)$ \\
\hline & $\begin{array}{l}\text { No. }(\%) \text { of patients receiving } \\
\text { itraconazole prophylaxis }\end{array}$ & $51 / 57(92 \%)$ \\
\hline & $\begin{array}{l}\text { No. }(\%) \text { of patients receiving } \\
\text { IFN- } \gamma \text { therapy }\end{array}$ & $34 / 57(60 \%)$ \\
\hline & $\begin{array}{l}\text { Age of initiation of IFN- } \gamma \\
\text { therapy, years, mean }\end{array}$ & $7.6 \pm 5.91$ years \\
\hline & $\begin{array}{c}\text { Duration of IFN- } \gamma \text { therapy, } \\
\text { median (range) }\end{array}$ & 26 (3-173) months \\
\hline
\end{tabular}

centrifuged at $400 \times \mathrm{g}$ and the supernatant was removed. The pellet was lysed by adding $1 \mathrm{ml}$ of lysing solution and was incubated for 15 minutes in the dark at room temperature. The tubes were washed twice with $1 \mathrm{ml}$ of washing solution [the mixture of 9 volumes of Cell wash (BD Biosciences, San Jose, CA) and 1 volume of foetal bovine serum (FBS, PAA Laboratories GmbH, Austria)]. The samples were run immediately on the flow cytometer (FACS Canto II, BD Biosciences, CA, USA).

\section{Flow cytometric analysis}

Flow cytometric analysis of the samples was performed on a FACS Canto II device (BD Biosciences, CA, USA) with FACS Diva Software (BD Biosciences, CA, USA). Acquisition templates of forward versus right-angle scatter signals were created and gated on the granulocyte and monocyte populations. Green fluorescence from
DHR was measured in the FL1 channel. We determined the stimulation index by calculating the ratio of the mean fluorescence of the stimulated cells to the mean fluorescence of the unstimulated cells, as described by Epling et al. [14]. The stimulation index was calculated separately for neutrophils and monocytes, before IFN- $\gamma$, after IFN- $\gamma$, and at hours 1 and 24.

\section{Statistical analysis}

The data obtained was analysed using SPSS for Windows (Version 18.0.0) statistical software. In the statistical evaluation, descriptive statistics were used. In the descriptive statistics of qualitative variables, frequencies and percentages were used, while in the descriptive statistics of quantitative variables, median (minimum, maximum) and mean \pm standard deviation were used. Both parametric and non-parametric analysis methods were used in the statistical analysis of variables. Regarding the dependent continuous variables, the paired $t$-test was used as the difference test when normal distribution was obtained, and the Wilcoxon test was used otherwise. The McNemar test was applied for dependent categorical variables. For the purpose of comparing the quantitative variables belonging to both groups, Student's $t$ test or Mann-Whitney $U$ test was used. Logistic regression analysis was used as the multivariable statistical analysis method. Statistical significance was assumed as $p<0.05$.

\section{Results}

\section{Demographic and clinical data}

Fourteen female and 34 male patients with CGD were studied, and the median age of the patients was 10.9 years (age range: 2-35 years). The mean age of the patients' diagnosis was $4.9 \pm 4.8$ years. The patients were divided into subgroups according to immunoblotting and/or genetic sequence analysis. As regards CGD subtypes, 16 (28\%) of them were gp91 ${ }^{\text {phox }}, 10(17.5 \%)$ of them were $\mathrm{p} 47^{\text {phox }}$, $10(17.5 \%)$ of them were p22 2 phox, $6(10.5 \%)$ of them were p6 $67^{\text {phox }}$, and $15(26 \%)$ of them were undetermined. Thirty-two of the patient families $(56 \%)$ had consanguineous marriage, and 34 of them $(60 \%)$ had a primary immunodeficiency (PID) history. The median duration of IFN- $\gamma$ therapy was 26 months (range: 3-173 months). The demographic data are shown in Table 1.

\section{Stimulation index}

Using the DHR-123 test, stimulation index (SI) values of neutrophils and monocytes of a total of 78 cases, of which 57 were patients and 21 were controls, were measured. Stimulation index values of the patient group were found to be prominently lower than in the control group $(p<0.001)$. While means of the SI values of the neutrophils and monocytes were $1.95 \pm 2.44$ and $2.68 \pm 4.00$, 
Table 2. Stimulation index of neutrophils of patients with chronic granulomatous disease before and after 1 and 24 hour after IFN- $\gamma$ adding

\begin{tabular}{cccc}
\hline Stimulation index (SI) & $\boldsymbol{n}$ & Median (min-max) & $\boldsymbol{p}$ \\
\hline SI (N) 0.h (IFN-) & 57 & $1.24(0.58-8.67)$ & 0.562 \\
\hline SI (N) 1.h (IFN+) & 57 & $1.14(0.44-11.95)$ & \\
\hline SI (N) 0.h (IFN-) & 57 & $1.24(0.58-8.67)$ & 0.012 \\
\hline SI (N) 24.h (IFN+) & 57 & $1.52(0.6-8.89)$ & \\
\hline SI (N) 1.h (IFN+) & 57 & $1.14(0.44-11.95)$ & 0.009 \\
\hline SI (N) 24.h (IFN+) & 57 & $1.52(0.6-8.89)$ & \\
\hline SI (N) - stimulation index of neutrophils & &
\end{tabular}

respectively, for patients, they were $89.5 \pm 72.7$ and 52.7 \pm 57.3 , respectively, for controls. Medians of the SI of neutrophils of the patients before in vitro IFN- $\gamma$ at hour 0 and after addition of IFN- $\gamma$ at hours 1 and 24 were compared in twos as hours 0-1, hours 0-24, and hours 1-24. While there was no statistically significant difference between hour 0 and hour 1, the differences between hours 0 and 24 and between hours 1 and 24 were significant (Table 2).

As regards monocytes, although there was a difference between hours 0 and 1, it was not statistically significant. There was no statistically significant difference between hours 0 and 24 and between hours 1 and 24 (Table 3).

In controls, medians of the SI of neutrophils and monocytes before in vitro IFN- $\gamma$ at hour 0 and after administration of IFN- $\gamma$ at hour 1 and hour 24 were compared in twos as hours $0-1$, hour 0-24, and hour 1-24, yielding no statistically significant difference.

\section{Stimulation indices of neutrophils and monocytes before IFN- $\gamma$ and after IFN- $\gamma$ at hour 1 and hour 24 with respect to chronic granulomatous disease subtypes}

When patients were compared with respect to CGD subtypes, in gp91 $91^{\text {phox }}$ subtype, while there was no difference in the neutrophils between hours 0 and 1 after IFN- $\gamma$, there was a difference between hours 1 and 24 although it was not statistically significant. On the other hand, the difference between hours 0 and 24 was determined as statistically significant. As regards monocytes, the differences between hours 0 and 1 and hours 0 and 24 were not significant, and the difference between hours 1 and 24 was not statistically significant although it was apparent. In P47phox vs. P22 $2^{\text {phox }}$ subgroups, no significant difference was determined in the SI values of neutrophils and monocytes after IFN- $\gamma$. In the p67 $7^{\text {phox }}$ subgroup there was no difference between hours 0 and 1 of neutrophils, but the differences between hours 0 and 24 and between hours 1 and 24 were statistically significant. No difference could be determined between hours $0-1,0-24$, and 1-24 of monocytes. As re-
Table 3. Stimulation index of monocytes of patients with chronic granulomatous disease before and after 1 and 24 hour after IFN- $\gamma$ adding

\begin{tabular}{cccc}
\hline Stimulation index (SI) & $\boldsymbol{n}$ & Median (min-max) & $\boldsymbol{p}$ \\
\hline SI (M) 0.h (IFN-) & 57 & $1.45(0.8-6.77)$ & 0.054 \\
\hline SI (M) 1.h (IFN+) & 57 & $1.31(0.7-6.58)$ & \\
\hline SI (M) 0.h (IFN-) & 57 & $1.45(0.8-.6 .77)$ & 0.431 \\
\hline SI (M) 24.h (IFN+) & 54 & $1.56(0.8-7.92)$ & \\
\hline SI (M) 1.h (IFN+) & 57 & $1.31(0.7-6.58)$ & \\
\hline SI (M) 24.h (IFN+) & 54 & $1.56(0.8-7.92)$ & \\
\hline SI (M) - stimulation index of monocytes & &
\end{tabular}

gards undetermined subtypes, there were some differences in neutrophils, particularly between hours 1-24 although they were not statistically significant. No difference was determined in monocytes (Tables 4, 5).

\section{Discussion}

In our study the oxidative bursting capacity of phagocytic cells in CGD was measured by DHR-123 test, and the effect of IFN- $\gamma$ on this activity was examined in vitro with DHR test by calculating SIs. Upon comparisons of the SIs of the patients' neutrophils before in vitro IFN- $\gamma$ ( 0 hour) and at hours 1 and 24 after addition of IFN- $\gamma$, a difference was determined between hours 0 and 24 and between hours 1 and 24 . This difference was particularly prominent between hours 1 and 24. This outcome led us to consider that the effect of IFN- $\gamma$ on neutrophils is likely to become more apparent over time. Similarly, in the study by Ishibashi et al. [15], it was demonstrated that, in some CGD subtypes (gp91 $\left.{ }^{\text {phox }}\right)$, IFN- $\gamma$ is effective on the neutrophils in the long term and increases the superoxide production. On the other hand, in our study, no apparent change was seen in the SIs upon addition of IFN- $\gamma$ in monocytes. When the effect of IFN- $\gamma$ was evaluated with respect to CGD subtypes, particularly in the gp $91^{\text {phox }}$ subtype, SIs of neutrophils after in vitro IFN- $\gamma$ were seen to be increasing after hour 1 , and that increase was further apparent at hour 24. Although the increase was also determined in the neutrophils of another subtype, p67 phox , because the number of patients was not enough, we suggest that studies on more patients related to the effect on this subtype should be made.

Inclusion of routine IFN- $\gamma$ addition to the anti-microbial treatment of cases with CGD is still controversial. In the early period studies related to the efficiency of IFN- $\gamma$ in CGD cases, in vivo or in vitro IFN- $\gamma$ was demonstrated to increase phagocyte superoxide production, and led to recovery in Staphylococcus aureus, Aspergillus killing test, and the nitro blue-tetrazolium (NBT) test response and a decrease the incidence of infection [7-10]. Upon demonstrating in ongoing multicentre studies that IFN- $\gamma$ 
Table 4. Stimulation index of neutrophils of patients with chronic granulomatous disease (CGD) according to subtypes before and after the $1^{\text {st }}$ and $24^{\text {th }}$ hour after interferon $\gamma$ addition

\begin{tabular}{|c|c|c|c|c|c|c|c|c|c|c|}
\hline $\begin{array}{l}\text { CGD subtype } \\
\text { (protein defect) }\end{array}$ & gp91 & & p47 phox & & p22 phox & & p6 $7^{\text {phox }}$ & & $\begin{array}{c}\text { Not } \\
\text { determined }\end{array}$ & \\
\hline $\begin{array}{l}\text { stimulation } \\
\text { index (SI) }\end{array}$ & $\begin{array}{c}\text { median } \\
(\min -\max )\end{array}$ & $p$ & $\begin{array}{c}\text { median } \\
(\min -\max )\end{array}$ & $p$ & $\begin{array}{c}\text { median } \\
(\text { min-max })\end{array}$ & $p$ & $\begin{array}{c}\text { median } \\
(\text { min-max })\end{array}$ & $p$ & $\begin{array}{c}\text { median } \\
(\text { min-max) }\end{array}$ & $p$ \\
\hline $\mathrm{SI}(\mathrm{N}) 0 . \mathrm{h}$ & $\begin{array}{c}1.17 \\
(0.9-1.7)\end{array}$ & \multirow{2}{*}{0.32} & $\begin{array}{c}2 \\
(0.6-8.6)\end{array}$ & \multirow{2}{*}{0.64} & $\begin{array}{c}1.4 \\
(1-5.7)\end{array}$ & \multirow{2}{*}{0.79} & $\begin{array}{c}0.89 \\
(0.6-1.4)\end{array}$ & \multirow{2}{*}{0.34} & $\begin{array}{c}1.15 \\
(0.7-1.7)\end{array}$ & \multirow{2}{*}{0.2} \\
\hline $\mathrm{SI}(\mathrm{N}) 1 . \mathrm{h}$ & $\begin{array}{c}1.13 \\
(1-1.73)\end{array}$ & & $\begin{array}{c}1.9 \\
(08-4)\end{array}$ & & $\begin{array}{c}1.1 \\
(0.8-4.1)\end{array}$ & & $\begin{array}{c}0.88 \\
(0.4-1.5)\end{array}$ & & $\begin{array}{c}1.21 \\
(0.7-1.4)\end{array}$ & \\
\hline $\mathrm{SI}(\mathrm{N}) 0 . \mathrm{h}$ & $\begin{array}{c}1.17 \\
(0.9-1.7)\end{array}$ & \multirow{2}{*}{0.02} & $\begin{array}{c}2 \\
(0.6-8.6) \\
\end{array}$ & \multirow{2}{*}{0.87} & $\begin{array}{c}1.4 \\
(1-5.7)\end{array}$ & \multirow{2}{*}{0.72} & $\begin{array}{c}0.89 \\
(0.6-1.4)\end{array}$ & \multirow{2}{*}{0.04} & $\begin{array}{c}1.15 \\
(0.7-1.7)\end{array}$ & \multirow{2}{*}{0.21} \\
\hline $\mathrm{SI}(\mathrm{N}) 24 . \mathrm{h}$ & $\begin{array}{c}1.36 \\
(1-2.3)\end{array}$ & & $\begin{array}{c}2.4 \\
(0.6-4.2)\end{array}$ & & $\begin{array}{c}1.48 \\
(1-6.5)\end{array}$ & & $\begin{array}{c}1.35 \\
(1-4.1)\end{array}$ & & $\begin{array}{c}1.3 \\
(1-2)\end{array}$ & \\
\hline $\mathrm{SI}(\mathrm{N}) 1 . \mathrm{h}$ & $\begin{array}{c}1.13 \\
(1-1.73)\end{array}$ & \multirow{2}{*}{0.07} & $\begin{array}{c}1.9 \\
(0.8-4)\end{array}$ & \multirow{2}{*}{0.48} & $\begin{array}{c}1.1 \\
(0.8-4.1)\end{array}$ & \multirow{2}{*}{0.50} & $\begin{array}{c}0.88 \\
(0.4-1.5)\end{array}$ & \multirow{2}{*}{0.04} & $\begin{array}{c}1.21 \\
(0.7-1.4)\end{array}$ & \multirow{2}{*}{0.07} \\
\hline $\mathrm{SI}(\mathrm{N}) 24 . \mathrm{h}$ & $\begin{array}{c}1.36 \\
(1-2.3)\end{array}$ & & $\begin{array}{c}2.4 \\
(0.6-4.2)\end{array}$ & & $\begin{array}{c}1.48 \\
(1-6.5)\end{array}$ & & $\begin{array}{c}1.35 \\
(1-4.1)\end{array}$ & & $\begin{array}{c}1.3 \\
(1-2)\end{array}$ & \\
\hline
\end{tabular}

SI (N) - stimulation index of neutrophils

Table 5. Stimulation index of monocytes of patients with chronic granulomatous disease (CGD) according to subtypes before and after the $1^{\text {st }}$ and $24^{\text {th }}$ hour after interferon $\gamma$ addition

\begin{tabular}{|c|c|c|c|c|c|c|c|c|c|c|}
\hline \multirow{2}{*}{$\begin{array}{c}\begin{array}{c}\text { CDG subtype } \\
\text { (protein defect) }\end{array} \\
\text { stimulation } \\
\text { index }(\mathrm{SI})\end{array}$} & \multicolumn{2}{|c|}{ gp91phox } & \multicolumn{2}{|c|}{ p47phox } & \multicolumn{2}{|c|}{ p22phox } & \multicolumn{2}{|c|}{ p67phox } & \multicolumn{2}{|c|}{ Not determined } \\
\hline & $\begin{array}{c}\text { median } \\
(\min -\max )\end{array}$ & $p$ & $\begin{array}{c}\text { median } \\
(\min -\max )\end{array}$ & $p$ & $\begin{array}{c}\text { median } \\
(\text { min-max })\end{array}$ & $p$ & $\begin{array}{c}\text { median } \\
(\text { min-max })\end{array}$ & $p$ & $\begin{array}{c}\text { median } \\
(\text { min-max })\end{array}$ & $p$ \\
\hline SI (M) 0.h & $\begin{array}{c}1.35 \\
(1.1-5.4)\end{array}$ & \multirow{2}{*}{0.25} & $\begin{array}{c}3 \\
(0.9-5.2)\end{array}$ & \multirow{2}{*}{0.95} & $\begin{array}{c}1.5 \\
(0.8-6.7)\end{array}$ & \multirow{2}{*}{0.06} & $\begin{array}{c}1.24 \\
(0.9-1.6)\end{array}$ & \multirow{2}{*}{0.34} & $\begin{array}{c}1.26 \\
(0.9-2.3)\end{array}$ & \multirow{2}{*}{0.15} \\
\hline SI (M) 1.h & $\begin{array}{l}1.25 \\
(1-4)\end{array}$ & & $\begin{array}{c}3 \\
(0.7-5.8)\end{array}$ & & $\begin{array}{c}1.59 \\
(0.9-6.5)\end{array}$ & & $\begin{array}{c}1 \\
(0.9-1.3)\end{array}$ & & $\begin{array}{c}1.2 \\
(0.9-2.5)\end{array}$ & \\
\hline SI (M) 0.h & $\begin{array}{c}1.35 \\
(1.1-5.4)\end{array}$ & \multirow{2}{*}{0.06} & $\begin{array}{c}3 \\
(0.9-5.2)\end{array}$ & \multirow{2}{*}{0.79} & $\begin{array}{c}1.5 \\
(0.8-6.7)\end{array}$ & \multirow{2}{*}{0.17} & $\begin{array}{c}1.24 \\
(0.9-1.3)\end{array}$ & \multirow{2}{*}{0.6} & $\begin{array}{c}1.26 \\
(0.9-2.3)\end{array}$ & \multirow{2}{*}{0.86} \\
\hline SI (M) 24.h & $\begin{array}{c}2 \\
(1-4) \\
\end{array}$ & & $\begin{array}{c}2.7 \\
(1.3-7.9) \\
\end{array}$ & & $\begin{array}{c}1.22 \\
(1.5-2 \\
\end{array}$ & & $\begin{array}{c}1.23 \\
(0.9-2) \\
\end{array}$ & & $\begin{array}{c}1.38 \\
(1-2.3) \\
\end{array}$ & \\
\hline SI (M) 1.h & $\begin{array}{l}1.25 \\
(1-4)\end{array}$ & \multirow{2}{*}{0.06} & $\begin{array}{c}3 \\
(0.7-5.8)\end{array}$ & \multirow{2}{*}{0.95} & $\begin{array}{c}1.59 \\
(0.9-6.5)\end{array}$ & \multirow{2}{*}{0.38} & $\begin{array}{c}1 \\
(0.9-1.3)\end{array}$ & \multirow{2}{*}{0.24} & $\begin{array}{c}1.2 \\
(0.9-2.5)\end{array}$ & \multirow{2}{*}{0.39} \\
\hline SI (M) 24.h & $\begin{array}{c}2 \\
(1-4)\end{array}$ & & $\begin{array}{c}2.7 \\
(1.3-7.9)\end{array}$ & & $\begin{array}{c}1.22 \\
(1.5-2)\end{array}$ & & $\begin{array}{c}1.23 \\
(0.9-2)\end{array}$ & & $\begin{array}{c}1.38 \\
(1-2.3)\end{array}$ & \\
\hline
\end{tabular}

SI $(M)$ - stimulation index of monocytes

treatment is well-tolerated and decreases the incidence and severity of infections, it has been included in routine treatment protocols, but the treatment has been seen not to increase the superoxide production of phagocytic cells [8-12]. On the other hand, in previous period studies on the efficiency of IFN- $\gamma$ in CGD, IFN- $\gamma$ treatment was shown to be likely to increase the superoxide production by changing the gene expression in oxidative components $[16,17]$. Ahlin et al. demonstrated that IFN- $\gamma$ caused a 3-5\% increase in the neutrophil superoxide production in two cases with X-linked gp91 ${ }^{\text {phox }}$ and in one case with $\mathrm{p} 67^{\text {phox }}$ subtype
[18]. As regards the recent period studies, Condino-Neto [19] and Ishibashi [15] suggested that IFN- $\gamma$ can be effective particularly in some variant CGD types with splice site mutation in $C Y B B$ gene transcripts. These outcomes suggest to us that, particularly in certain subgroups of CGD cases, recombinant interferon $\gamma(\mathrm{r}-\mathrm{IFN}-\gamma)$ treatment can be effective and can increase the superoxide production.

In our study, genotyping could be made precisely in only 14 of the 57 cases. Since the number of patients for whom genotyping could be made was small, it was not possible to show how and in which group IFN- $\gamma$ affected 
the mutations. Moreover, it was not possible to understand the effect of likely mutations in the subtypes of NADPH oxidase enzyme complex on the protein expression and on the SI value indicating the production of residual reactive oxygen intermediate products. In our opinion, conducting studies on more cases for which detailed genotyping can be made is an issue worth pursuing.

In our study we demonstrated, in support of the literature, that in vitro r-IFN- $\gamma$ increases SIs on neutrophils and can increase the superoxide production, especially with respect to certain subtypes (gp91 ${ }^{\text {phox }}$ ). In our previous study [20] examining the incidence of infectious and other complications in CGD cases before and after IFN- $\gamma$, the patients receiving IFN- $\gamma$ therapy tended to have lower infectious complications like severe infections, pneumonia, soft tissue infections, and lymphadenitis. Aspergillus infection, tissue abscesses, and granulomatous complications were also lower in this group. The annual infectious complications with respect to CGD subtypes were also lower in $\mathrm{gp} 91^{\text {phox }}$ receiving IFN- $\gamma$ therapy. We also determined that $\mathrm{gp} 91^{\text {phox }}$ was the one mostly receiving IFN- $\gamma$ treatment among the subtypes.

Interferon $\gamma$ has pleiotropic effects on the immune system. It has been shown to be important to the functioning and maturation of multiple immune cells. Interferon $\gamma$ recruits neutrophils, stimulates them to upregulate chemokine, and triggers rapid superoxide production and respiratory burst. Interferon $\gamma$ increases the cytotoxic and phagocytic activity of macrophages as well [21,22]. Other possible explanations regarding the mechanism of action of IFN- $\gamma$ in CGD, like improved neutrophil microbicidal killing through mechanisms other than the respiratory burst, may also be important, and that could clarify the clinical benefits of IFN- $\gamma$ in CGD patients. However, the definite mechanism of the therapeutic effect of IFN- $\gamma$ still needs further studies.

Although we think that there will be further studies on the place and efficiency of IFN- $\gamma$ treatment in CGD, our study demonstrated that IFN- $\gamma$ treatment can be effective, especially on neutrophils, by increasing the superoxide production and thus increasing the oxidative bursting activity, particularly with respect to gp $91^{\text {phox }}$ subtype. We suggest that measuring the in vitro effect of IFN- $\gamma$ in CGD cases by DHR test at diagnosis and increasing the amount of prospective research and clinical observation data of broader series about the relationship of the data obtained as a results of these measurements with the genotypic data of the patient shall be beneficial for the clinicians at initiating the IFN- $\gamma$ treatment, which is an expensive treatment alternative, in making patient-specific decisions.

The authors declare no conflict of interest.

Serkan Filiz drafted the manuscript, Dilara F. Kocacik Uygun and Olcay Yeğin, co-write the draft manuscript, Sadi Köksoy and Emel Şahin, make-up the labora- tory analsysis. All of the authors read and approved the final version of the manuscript. This work was supported by Akdeniz University Scientific Research Foundation (2012.04.0103.008).

Consent: Informed consent was obtained from each healthy volunteer and all patients with CGD or from their guardians before their enrollment to the study.

We are grateful to the following members of Turkish Pediatric Allergy \& Immunology Departments authors for their help with kindly co-operation The authors are: Özden SANAL, M.D, Unit of Pediatric Immunology, Faculty of Medicine, Hacettepe University, Ankara, Turkey, Ylldiz CAMCIOĞLU, M.D, Division of Pediatric Allergy and Immunology, Department of Children's Health and Diseases, Faculty of Cerrahpasa Medicine, Istanbul University, Istanbul, Turkey, Ayper SOMER, M.D, Division of Children's Infectious Diseases and Clinical Microbiology, Department of Children's Health and Diseases, Faculty of Istanbul Medicine, Istanbul University, Istanbul, Turkey, Işıl BARLAN, M.D, Unit of Pediatric Allergy \& Immunology Marmara University Training and Research Hospital, Istanbul, Turkey, Şebnem KILIÇ,M.D, Division of Pediatric Immunology, Department of Children's Health and Diseases, Faculty of Medicine, Uludağ University, Bursa, Turkey, İsmail REISLI, M.D, Division Pediatric Immunology-Allergy, Department of Children's Health and Diseases, Faculty of Meram Medicine, Konya Necmettin Erbakan University, Konya, Turkey, Türkan PATIROĞLU,M.D, Division of Pediatric Hematology and Oncology, Department of Children's Health and Diseases, Faculty of Medicine, Erciyes University, Kayseri, Turkey, Alişan YILDIRAN, M.D, Division of Pediatric Allergy and Immunology, Department of Children's Health and Diseases, Faculty of Medicine, Ondokuz Mayıs University, Samsun, Turkey, Hasibe ARTAÇ, M.D, Division of Pediatric Immunology and Allergy, Department of Children's Health and Diseases, Faculty of Selçuklu Medicine, Selcuk University, Konya, Turkey, Ayșe METIN, M.D, Clinic of Pediatric Allergy and Immunology, Department of Pediatric Immunology, Ankara Pediatric and Pediatric Hematology Oncology Training and Research Hospital, Ankara, Turkey, Güzide AKSU, M.D, Division of Pediatric Allergy and Immunology, Department of Children's Health and Diseases, Faculty of Medicine, Ege University, Izmir, Turkey, Ferah GENEL, M.D, Division of Pediatric Allergy and Immunology, Department of Children's Health and Diseases, Izmir Dr. Behcet Uz Children Hospital, Izmir, Turkey, Can ÖZTÜRK, M.D, Clinic of Pediatric Immunology and Romatology, Izmir Tepecik Training and Research Hospital, Izmir, Turkey, Fatih Çelmeli, M.D, Clinic of Pediatric Allergy \& Immunology, Antalya Training \& Research Hospital, Antalya, Turkey.

We are grateful to the patients and their families for the participation in this study. 


\section{References}

1. Rosenzweig SD, Holland SM (2004): Phagocyte immunodeficiencies and their infections. J Allergy Clin Immunol 113: 620-626.

2. Holland SM (2010): Chronic granulomatous disease. Clinic Rev Allerg Immunol 38: 3-10.

3. de Oliveira-Junior EB, Bustamante J, Newburger PE, et al. (2011): The human NADPH oxidase: primary and secondary defects impairing the respiratory burst function and the microbicidal ability of phagocytes. Scand J Immunol 73: 420-427.

4. Song E, Jaishankar GB, Saleh H, et al. (2011): Chronic granulomatous diseases: a review of the infectious and inflammatory complications. Clin Mol Allergy 9: 1-14.

5. Kang EM, Marciano BE, De Ravin S (2011): Chronic granulomatous disease: overview and hematopoietic stem cell transplantation. J Allergy Clin Immunol 127: 1319-1326.

6. Saha B, Prasanna SJ, Chandrasekar B, Nandi D (2010): Gene modulation and immunoregulatory roles of interferon- $\gamma$. Cytokine 50: 1-14.

7. Ezekowitz RA, Orkin SH, Newburger PE (1987): Recombinant interferon gamma augments phagocyte superoxide production and $\mathrm{X}$-chronic granulomatous disease gene expression in X-linked variant chronic granulomatous disease. J Clin Invest 80: 1009-1016.

8. A controlled trial of interferon gamma to prevent infection in chronic granulomatous disease. The International Chronic Granulomatous Disease Cooperative Study Group (1991): N Engl J Med 324: 509-516.

9. Woodman RC, Erickson RW, Rae J, et al. (1992): Prolonged recombinant interferon-gamma therapy in chronic granulomatous disease: evidence against enhanced neutrophil oxidase activity. Blood 79: 1558-1562.

10. Weening RS, Leitz GJ, Seger RA (1995): Recombinant human interferon-gamma in patients with chronic granulomatous disease-European follow-up. Eur J Pediatr 154: 295-298.

11. Jackson SH, Miller GF, Segal BH, et al. (2001): IFN- $\gamma$ is effective in reducing infections in the mouse model of chronic granulomatous disease. J Interferon Cytokine Res 21: 567-573.

12. Marciano BE, Wesley R, De Carlo ES, et al. (2004): Longterm interfeon- $\gamma$ therapy for patients with chronic granulomatous disease. Clin Infect Dis 39: 692-699.

13. Hawley TS, Hawley RG (eds.) (2004): Methods in Molecular Biology: Flow Cytometry Protocols. 3rd ed. Humana Press Inc. Totowa, NJ.

14. Epling CL, Stites DP, McHugh TM, et al. (1992): Neutrophil function screening in patients with chronic granulomatous disease by a flow cytometric method. Cytometry 13: 615-20.

15. Ishibashi F, Mizukami T, Kanegasaki S, et al. (2001): Improved superoxide-generating ability by interferon- $\gamma$ due to splicing pattern change of transcripts in neutrophils from patients with splice site mutation in CYBB. Blood 98: 436-441.

16. Newburger PE, Ezekowitz RAB, Whitney C, et al. (1988): Introduction of phagocyte cytochrome b heavy chain gene expression by interferon- $\gamma$. Proc Natl Acad Sci U S A 85: 5215-5219.

17. Cassatella MA, Bazzoni F, Flynn RM, et al. (1990): Molecular basis of interferon- $\gamma$ and lipopolysaccharide enhancement of phagocyte respiratory burst capability. Studies on the gene expression of several NADPH oxidase components. J Biol Chem 265: 20241-20246.

18. Ahlin A, Elinder G, Palmblad J (1997): Dose-dependent enhancements by interferon- $\gamma$ on functional responses of neu- trophils from chronic granulomatous disease patients. Blood 89: 3396-3401.

19. Condino-Neto A, Newburger PE (2000): Interferon-gamma improves splicing efficiency of CYBB gene transcripts in an interferon-responsive variant of chronic granulomatous disease due to a splicing site consensus region mutation. Blood 95: 3548-3554.

20. Filiz S, Kocacık Uygun DF, Sanal O, et al. (2013): The demographic datas of chronic granulomatous disease patients and the comparation of the clinical datas before and after interferon-gamma treatment in our country. Asthma Allergy Immunology 11: 152-161.

21. Miller CH, Maher SG, Young HA (2009). Clinical use of interferon- $\gamma$. Ann N Y Acad Sci 1182: 69-79.

22. Errante PR, Frazao JB, Condino-Neto A (2008): The use of interferon-gamma therapy in chronic granulomatous disease. Recent Pat Antiinfect Drug Discov 3: 225-230. 